\title{
Schistosomiasis in Sub-Sahara Africa: Causes, Consequences and Control Measures for a Leading Neglected Tropical Disease
}

\author{
Yandev D. ${ }^{1,3}$, Chigor V. N. ${ }^{1}$, Eze E. A. ${ }^{2}$, Akosu D. D. ${ }^{3}$, Okorie
${ }^{1}$ Department of Microbiology, Water and Public Health Research Group, University Of Nigeria Nsukka
${ }^{2}$ Department of Microbiology, University Of Nigeria Nsukka \\ ${ }^{3}$ Department of Biological Science, University of Mkar, Gboko, Benue State
}

\begin{abstract}
Summary: This paper reviews the causes, consequences and control measures of schsistosomiasis in Sub Sahara Africa. It is a worrisome parasitic disease caused by flukes (trematodes) of the genus Schistosoma. High prevalence rates exist in most part of Africa due to many associated factors. People become infected when larval forms of the parasite (released by freshwater snails) penetrate the skin during contact with infested water. Although it is classified under the neglected Tropical diseases, it has continued to result in life threatening complications and mortalities most especially as it affects body organs. Many factors that are associated with the disease have been discussed. So far, control programmes have proven effective despite the geometric increase in human population in Africa. Large scale treatments of population groups most especially in endemic regions have been carried out. The major set back in the treatment is lack of comprehensive data on the prevalence of schistosomiasis in many populations. In spite of this, World health Organisation has rolled out guidelines and mandates on the prevention and control of schistosomiasis in sub Saharan Africa and other places. Access to safe water, improved sanitation, hygiene education, and snail control are possible control measures reported so far in literatures. The future control measure of schistosomiasis is likely to be based on the discovery and adoption of cheap novel drugs, schistosomicides and vaccines to combat the worrisome infection in the sub Saharan Africa and other places in the Tropics.
\end{abstract}

\section{Introduction}

Schistosomiasis or bilharzia is a neglected tropical parasitic disease caused by the larvae of one or more of five types of blood flukes called schistosomes. It counts as the second most devastating tropical parasitic disease worldwide after malaria with more than 200 millions of cases mainly in rural agricultural and peri-urban areas of developing countries (Chistulo et al.,2004; WHO, 2018). About 80-85\% of the disease is now found in sub-Saharan Africa, and the number of people infected is alarming. Unfortunately, the impact of schistosomiasis has long been under-estimated compared to that of malaria and tuberculosis (Adeyeba and Ojeaga, 2002). Cases of complications manifesting from acute and chronic schistosomiasis have been reported in many parts of Africa (Gryseels, 1991; Colley et al., 2001; Ross et al., 2010; Leshem et al., 2008; Adenowo et al., 2015). With the high prevalent rates also reported in many places (Gberikon et al., 2015; Magaisa et al., 2015; Adenowo et al.,2015), it has become necessary to create awareness on issues bordering on the infection as the first step in disease control programme. The present review aims at dissecting the causes, consequences and possible remedy of schistosomiasis in sub Saharan Africa.

\begin{abstract}
Epidemiology and Prevalence of Schistosomiasis in Sub-Saharan Africa

Schistosomiasis is a parasitic disease caused by flukes (trematodes) of the genus Schistosoma. According to the World Health Organisation, it is the second most devastating tropical disease in the world, being a major source of morbidity and mortality for developing countries in Africa, South America, the Caribbean, the Middle East, and Asia (Gryseels, 1991; Abebe et al., 2014; WHO, 2016). It is also known as bilharzias, bilharziasis, or snail fever. This infection was discovered by Theodore Bilharz, a German surgeon working in Cairo, who first identified the etiological agent Schistosoma hematobium in 1851 (Adeyeba and Ojeaga, 2002). Schistosomiasis is an acute and chronic parasitic disease. Most human schistosomiasis is caused by $S$ haematobium, $S$ mansoni, and $S$ japonicum. Less prevalent species, such as $S$ mekongi and $S$ intercalatum, may also cause systemic human disease (Abebe et al., 2014; Adeyeba and Ojeaga, 2002). There are other schistosomes primarily hosted by birds and mammals that can cause severe dermatitis in humans but they are not as important as those hosted by fresh water snails (Colley et al., 2001). Etiology of schistosomiasis reflects the unique life cycle of Schistosoma species (Figure 1).
\end{abstract}

This article is published under the terms of the Creative Commons Attribution License 4.0 Author(s) retain the copyright of this article. Publication rights with Alkhaer Publications. Published at: http://www.ijsciences.com/pub/issue/2019-07/

DOI: 10.18483/ijSci.2103; Online ISSN: 2305-3925; Print ISSN: 2410-4477 
Schistosomiasis is highly prevalent in tropical and sub-tropical areas most especially the sub Saharan African countries (Abebe et al., 2014). It is mostly endemic in poor communities that lack access to safe drinking water, clean environment, good hygiene and adequate sanitation (Anto et al., 2013). It is estimated that at least $91.4 \%$ of those requiring treatment for schistosomiasis live in Africa (Mcman, 2002). There are 2 major forms of schistosomiasis as shown in Table 1. They are: intestinal and urogenital schistosomiasis.

Table 1: Geographical Distribution of Schistosomiasis

\begin{tabular}{lll}
\hline Type & Species & Geographical distribution \\
\hline Intestinal schistosomiasis & $\begin{array}{l}\text { Schistosoma mansoni } \\
\text { Schistosoma japonicum }\end{array}$ & $\begin{array}{l}\text { Africa, the Middle East, the Caribbean, Brazil, } \\
\text { Venezuela and Suriname }\end{array}$ \\
& Schistosoma mekongi & $\begin{array}{l}\text { China, Indonesia, the Philippines } \\
\text { Peveral districts of Cambodia and the Lao }\end{array}$
\end{tabular}

Schistosoma guineensis and

Rain forest areas of central Africa

S. intercalatum

Urogenital/Urinary Schistosoma haematobium

Africa, the Middle East, Corsica (France)

schistosomiasis

Source: World Health Organization (2016)

http://www.who.int/healthinfo/global_burden_disease/estimates/en/index1.html

Many factors have been linked to the infection as reported in literatures. For instance, it mostly affects poor and rural communities, particularly in agricultural and fishing populations. The risk of infection is highest amongst those living near lakes or rivers. Inadequate hygiene, contact with infected water and playing in the mud make children vulnerable to infection. Women fond of washing clothes in water infested with schistosomes are at risk. Migration to urban areas, tourism and population movements are spreading the disease to new areas (Corachan, 2002). Poverty, population explosion and the needs for water for domestic and farming activities have also been implicated (Anto et al., 2013). Today, 120 million people are symptomatic with schistosomiasis, with 20 million having severe clinical disease resulting in more than 200,000 deaths per year in sub-Saharan Africa (WHO 2016; CDC 2008). An estimated 700 million people are at risk of infection in 76 countries where the disease is considered endemic (WHO 2016). Forty million women of childbearing age are infected. Approximately 10 million women in Africa have schistosomiasis during pregnancy (Friedman et al., 2007).

The WHO recommended less than 5\% prevalence rate of schistosomiasis of any type in any community (WHO, 2016). Most studies have revealed high endemicity in many parts of sub Saharan African countries (Adenowo et al., 2015). Most reports so far were far higher than the WHO limit (Table 2). The degree of prevalence varies from place to place depending on the type of subjects evaluated (children/adult/pregnant mothers), mixed infections, habitat type (riverine/plain), occupational status and other demographic parameters (Adeyeba and Ojeaga, 2002; Anto et al., 2013; Salawu and Odaibo, 2013; Gberikon et al., 2015). Table 2 presents the outcomes of selected studies on the prevalence of the disease in Nigeria.

Table 2: Prevalence of Schistosomiasis in Nigeria

\begin{tabular}{l|l|c|l}
\hline Geographical Area & Type of Schistosomiasis & Prevalence (\%) & Source \\
\hline $\begin{array}{l}\text { Yewa North Local } \\
\text { Government of Ogun State, } \\
\text { Nigeria }\end{array}$ & $\begin{array}{l}\text { Urinary schiatosomiasis } \\
\text { among pregnant women }\end{array}$ & 20.8 & Salawu and Odaibo, 2013 \\
Sokoto,Northern Nigeria & Urinary schiatosomiasis & 60.8 & Kiran and Jitendra, 2016 \\
$\begin{array}{l}\text { Sokoto,Northen Nigeria } \\
\text { Gboko Benue State, North }\end{array}$ & Untestinal schistosomiasis & 2.93 & Kiran and Jitendra, 2016 \\
Central Nigeria & & 11 & Gberikon et al., 2015 \\
\hline
\end{tabular}


Schistosomiasis in Sub-Sahara Africa: Causes, Consequences and Control Measures for a Leading Neglected Tropical Disease

\begin{tabular}{l|l|c|l}
\hline $\begin{array}{l}\text { Abeokuta North Ogun State, } \\
\text { South West Nigeria }\end{array}$ & Urinary schiatosomiasis & 52.7 & Otuneme et al., 2014 \\
$\begin{array}{l}\text { Ndokwa East LGA, Delta } \\
\text { State, South South Nigeria }\end{array}$ & Urinary schistosomiasis & 91.4 & Nwabueze and Opara, 2007 \\
\hline
\end{tabular}

\section{Life Cycle of Schistosomes}

Schistosomes infect susceptible freshwater snails in endemic areas, usually with specific species of schistosomes infecting specific species of snails (Biomphalaria for S. mansoni; Oncomelania for S. japonicum; Neotricula aperta for S. mekongi; Bulinus for $S$. haematobium and S. intercalatum) (Abebe et al., 2014). Reports on the lifecycle of the infection are the same in all literatures (Lapa et al., 2009). The infected snails release cercariae in waster 4-6 weeks after infection. The cercariae are fork-tailed, freeswimming larvae approximately $1 \mathrm{~mm}$ in length. They can survive in fresh water up to 72 hours, during which time they must attach to human skin or to that of another susceptible host mammal or die. Successful cercariae attach to human hosts, utilizing oral and ventral suckers. They then migrate through intact skin to dermal veins and, over the next several days, to the pulmonary vasculature. During this migration, the cercariae metamorphose, shedding tails and outer glycocalyces while developing doublelipid-bilayer teguments that are highly resistant to host immune responses. The organisms, now called schistosomula, incorporate host proteins, including major histocompatibility complexes (MHCs) and blood group antigens, into their integuments. Their metabolism shifts to glycolysis. The worms then migrate through the pulmonary capillaries to the systemic circulation, which carries them to the portal veins, where they mature.
Within the portal vasculature, male and female adults pair off, with the thin female entering and remaining in the gynecophoric canal of the stockier $8 \mathrm{~mm}$ male worm. Together they migrate along the endothelium, against portal blood flow, to the mesenteric ( $S$ mansoni, S japonicum) or vesicular (S haematobium) veins, where they begin to produce eggs (Lapa et al., 2009). The microscopic appearance of the egg allows diagnostic differentiation of the 5 species. An adult $S$ haematobium produces 20-200 round, terminally spined eggs per day (see the image below); $S$ mansoni produces 100-300 ovoid, laterally spined eggs per day; and S japonicum produces 500-3500 small, round, laterally spined eggs per day. The eggs of $S$ intercalatum have prominent, terminal spines, and those of $S$ mekongi have small, lateral spines. The eggs, which are highly antigenic and can induce an intense granulomatous response, migrate through the bowel or bladder wall to be shed via feces or urine. During this time (approximately 10 days), the organisms begin to mature into miracidia (Lapa et al., 2009). Eggs that are not shed successfully may remain in the tissues or be swept back to the portal circulation (from the mesenteric vessels) or to the pulmonary circulation (from the vesicular vessels via the inferior vena cava). Eggs can end up in the skin, brain, muscle, adrenal glands, and eyes. As the eggs penetrate the urinary system, they can find their way to the female genital region and form granulomas in the uterus, fallopian tube, and ovaries.

The adult worms are small, $12-26 \mathrm{~mm}$ long and 0.3 $0.6 \mathrm{~mm}$ wide, and vary with the different species.

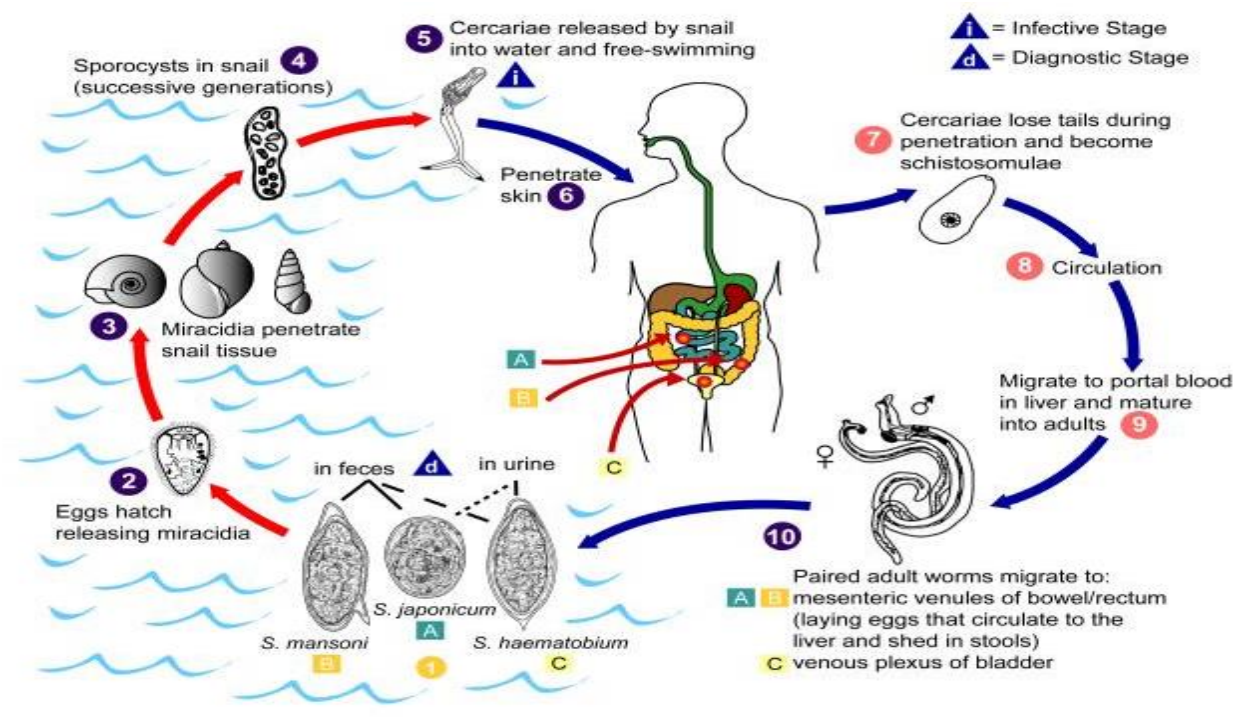

Figure 1: Life Cycle and Mechanism of Infection in Schistosomiasis

Source: The Michael Hsieh Lab - Stanford University (http//:www.uti.standford.edu/research) 
CNS involvement occurs because of embolization of eggs from the portal mesenteric system to the brain and spinal cord via the paravertebral venous plexus (Walker and Zunt, 2005). The free-swimming miracidia that are shed into fresh water survive 1-3 weeks, during which time they must infect a susceptible snail to complete the life cycle. Within the infected snail, 2 generations of sporocysts multiply, mature into free-swimming cercariae, and exit the snail to seek a human host and begin a new cycle. In the case of $S$ japonicum, which may be the species with the highest risk of complications, the life cycle may include domesticated animals such as cattle and wild animals (Walker and Zunt, 2005).

\section{Possible Effects of Socio-demographics on} Schistosomiasis

From many reports on schistosomiasis so far (Adeyeba and Ojeaga, 2002; Gberikon et al., 2015), some sociodemographic factors have been implicated. The frequency of infection among individuals of specific races is based on the geographic distribution of endemic schistosomiasis in large tropical and subtropical regions of Africa, Asia, the Middle East, and the Caribbean (Augusto et al., 2009). However, all humans appear equally susceptible if exposed to infested fresh water. The frequency of some complications appears to vary geographically during infection with the same worm species (Augusto et al., 2009). Schistosomiasis is more common in males, most likely because of increased exposure to infected water via bathing, swimming, and agricultural activities. The prevalence and severity of schistosomal infections vary with age (Gberikon et al., 2015). Children and adolescents are infected most often and are infested most heavily. Infection rates and severity may vary with genderspecific activity at all ages (Gberikon et al., 2015). Globally, infections peak in individuals aged 10-19 years. In some areas, the prevalence in this group may approach $100 \%$. In persons older than age 19 years living in endemic areas, the prevalence of active infection and egg counts slowly declines (Augusto et al., 2009).

\section{Consequences of Schistosomiasis}

(a) Complications

Schistosomiasis is due to immunologic reactions to Schistosoma eggs trapped in tissues. Antigens released from the egg stimulate a granulomatous reaction involving $\mathrm{T}$ cells, macrophages, and eosinophils that results in clinical disease (Adenowo et al., 2015, CDC, 2008). Symptoms and signs depend on the number and location of eggs trapped in the tissues. Initially, the inflammatory reaction is readily reversible. In the latter stages of the disease, the pathology is associated with collagen deposition and fibrosis, resulting in organ damage that may be only partially reversible (Mohammed et al., 2007; CDC, 2008). Eggs can end up in the skin, brain, muscle, adrenal glands, and eyes. As the eggs penetrate the urinary system, they can find their way to the female genital region and form granulomas in the uterus, fallopian tube, and ovaries (Mohammed et al., 2007). Central nervous system (CNS) involvement occurs because of embolization of eggs from the portal mesenteric system to the brain and spinal cord via the paravertebral venous plexus (Mohammed et al., 2007).

Acute schistosomiasis is associated with a mortality rate of up to $25 \%$ in some series (Leshem et al., 2008). Although most individuals with chronic schistosomiasis have few or no symptoms, significant morbidity can develop (CDC, 2008). Complaints are difficult to quantitate because of the geographic distribution of this infection in developing nations and the frequency of co-morbid conditions such as viral hepatitis (Lapa et al., 2009). Hepatosplenic disease with portal hypertension is the most common long-term, serious outcome, followed by cardiopulmonary involvement, obstructive nephropathy, bacteremia, and malignancy. Female genital infection can contribute to pregnancy complications, including reports of related ectopic pregnancy (Friedman et al., 2007; CDC, 2008). Urogenital schistosomiasis is considered to be a risk factor for HIV infection, especially in women. Endstage hepatosplenic disease with variceal bleeding, pulmonary hypertension with cor pulmonale, and central nervous system disease are associated with high mortality rates (Lapa et al., 2009; Mbabazi et al., 2011). Carcinoma of the urinary tract, liver, and gallbladder may cause death.

\section{(b) Effects of Acute and Chronic Schistosomiasis}

Acute schistosomiasis also known as the Katayama syndrome is a systemic, serum sickness-like illness that develops after several weeks. It may correspond to the first cycle of egg deposition and is associated with marked peripheral eosinophilia and circulating immune complexes (Leshem et al., 2008; Adenowo et al., 2015). Mild, maculopapular skin lesions may develop in acute infection within hours after exposure to cercariae. Significant dermatitis is rare with the major human schistosomal pathogens, probably because the invading and developing cercariae are minimally immunogenic (Leshem et al., 2008; van Lieshout et al., 2000).

The pathology of chronic schistosomiasis is more common than the acute form of the infection. It results from egg-induced immune response, granuloma formation, and associated fibrotic changes (van Lieshout et al., 2000; Leshem et al., 2008). Although cercarial and adult worms are minimally immunogenic, schistosomal eggs are highly immunogenic and induce vigorous circulating and local immune responses (van Lieshout et al., 2000; 
Mohammed et al., 2007). Adult worms can absorb host proteins. If not attacked by the immune system, they can live for years in the blood stream as they are coated with host antigens. Egg retention and granuloma formation in the bowel wall (usually $S$ mansoni or $S$ japonicum) may cause bloody diarrhea, cramping, and, eventually, inflammatory colonic polyposis (Leshem et al., 2008). Patients with heavy bowel wall involvement have an increased rate of recurrent Salmonella infection, generally with positive blood cultures and negative stool cultures (Leshem et al., 2008). Chronic intestinal schistosomiasis can present with acute complications of appendicitis, perforation, and bleeding long after travel-related (or endemic) exposure (Seck et al. 2011).

Rectal perforation caused by $S$ haematobium has also been described in a case report (Seck et al., 2011). Heavy infestations are more likely to produce hepatic disease. Eventually, severe periportal fibrosis in a characteristic pipestem pattern. Periportal fibrosis can lead to portal hypertension with the usual potential sequelae, including splenomegaly, ascites, esophageal variceal bleeding, and development of portosystemic collaterals. Eggs can reach the pulmonary circulation. The resulting pulmonary granulomatosis and fibrosis can lead to pulmonary hypertension with a high mortality rate (Mohammed et al., 2007; Lapa et al., 2009). Co-infection with hepatitis B or hepatitis C can accelerate hepatic dysfunction and raise the risk for hepatocellular carcinoma beyond that seen with hepatitis alone (Lapa et al., 2009). In addition, gallbladder cancer may be associated with schistosomal infection. Egg retention and granuloma formation in the urinary tract (S haematobium) can lead to hematuria, dysuria, bladder polyps and ulcers, and even obstructive uropathies. $S$ haematobium infection is also associated with an increased rate of bladder cancer, usually squamous cell rather than transitional cell (Lapa et al., 2009).

\section{(c) Gastrointestinal and Urinary tract Schistosomiasis}

The most common complication of GI schistosomiasis is periportal fibrosis, also termed Symmers pipestem fibrosis (Adenowo et al., 2015). This leads to portal hypertension and GI hemorrhage. Among persons with $S$ mansoni, $S$ japonicum, and, possibly, $S$ mekongi, 4-8\% develop hepatosplenic disease (Mohammed et al., 2007; Lapa et al., 2009). People co-infected with either hepatitis B or C and $S$ mansoni have been shown to have rapid progression of liver disease (Lapa et al., 2009). Urinary tract schistosomiasis can lead to renal failure due to obstructive uropathy, pyelonephritis, or bladder carcinoma. In addition, immune complexes that contain worm antigens may deposit in the glomeruli, leading to glomerulonephritis and amyloidosis (Lapa et al., 2009). Seck et al. (2011) reported cases of membranoproliferative glomerulonephritis (MPGN) associated with Schistosoma hematobium infection in a young Senegalese boy living in a rural area. Clinical presentation was with steroid-resistant with nephrotic syndrome.

\section{(d) Female genital schistosomiasis and coexistence with sexually transmitted infection}

$S$ haematobium causes lesions in the female lower genital tract such as cervix, valve and vagina. Female genital schistosomiasis has been identified as a major social and medical problem that may facilitate the spread of some sexually transmitted diseases, such as HIV, human papillomavirus (HPV), Neisseria gonorrhoeae, Chlamydia trachomatis, Mycoplasma genitalium, Trichomonas vaginalis and other STIs ((Adeyeba and Ojeaga, 2002; Mbabazi et al., 2011; Gberikon et al., 2015).

\section{(e) CNS schistosomiasis}

Because of its smaller egg size, $S$ japonicum causes $60 \%$ of all Schistosoma brain infections, with CNS involvement occurring in $2-4 \%$ of all $S$ japonicum infections (Walker and Zunt, 2005). Nodular, enhancing cerebellar lesions can occur as well with this species. However, CNS schistosomiasis can also occur with other species (Walker and Zunt, 2005). Spinal schistosomiasis usually presents as transverse myelitis and is primarily due to $S$ mansoni infection because of the larger egg size

\section{(f) Economic loss and financial burden}

The neglected tropical diseases exert great health, social and financial burden on economies of households and governments (Gryseels, 1991; Adenowo et al., 2015). Diagnosis, prevention and control exert huge financial burden to stakeholders. Comprehensive researches on the disease across wide geographical areas are expensive most especially when molecular tools are applied. Hence, meaningful research on shistosimiasis requires huge funding. Schistosomiasis has profound negative effects on child development, outcome of pregnancy, and agricultural productivity (Friedman et al., 2007; Adenowo et al., 2015).

\section{Control of Schistosomiasis}

The control of schistosomiasis is based on large-scale treatment of at-risk population groups, access to safe water, improved sanitation, hygiene education, and snail control (Gryseels, 1991; Fenwick et al., 2002; Anto et al., 2013; Magaisa et al., 2015). The WHO strategy for schistosomiasis control focuses on reducing disease through periodic, targeted treatment with praziquantel through the large-scale treatment (preventive chemotherapy) of affected populations (Berge et al., 2011; Magaisa et al., 2015). It involves regular treatment of all at-risk groups. In a few countries, where there is low transmission, the 
interruption of the transmission of the disease should be aimed for. Groups targeted for treatment are: school-aged children in endemic areas, adults considered to be at risk in endemic areas and people with occupations involving contact with infested water, (such as fishermen, farmers, irrigation workers, and women whose domestic tasks bring them in contact with infested water) (Anto et al., 2013; Gberikon et al., 2015). The entire communities living in highly endemic areas are also targeted. The frequency of treatment is determined by the prevalence of infection in school-age children. In high-transmission areas, treatment may have to be repeated every year for a number of years. Monitoring is essential to determine the impact of control interventions (Fenwick et al., 2002).

The WHO aim is to reduce disease morbidity and transmission: periodic treatment of at-risk populations will cure mild symptoms and prevent infected people from developing severe, late-stage chronic disease (Fenwick et al., 2002; CDC, 2008; WHO, 2016). However, a major limitation to schistosomiasis control has been the limited availability of praziquantel. Data for 2016 showed that $35.6 \%$ of people requiring treatment were reached globally, with a proportion of $53.7 \%$ of school-aged children requiring preventive chemotherapy for schistosomiasis being treated (WHO, 2016). Praziquantel is the recommended treatment against all forms of schistosomiasis (Berge et al., 2011; Nkengazong et al., 2013; Magaisa et al., 2015; WHO, 2016). It is effective, safe, and low-cost (Berge et al., 2011; Nkengazong et al., 2013). Even though re-infection may occur after treatment, the risk of developing severe disease is diminished and even reversed when treatment is initiated and repeated in childhood. Schistosomiasis control has been successfully implemented over the past 40 years in several countries, including Brazil, Cambodia, China, Egypt, Mauritius, Islamic Republic of Iran, Oman, Jordan and Saudi Arabia. Over the past 10 years, there has been scale-up of treatment campaigns in a number of sub-Saharan countries, where most of those at risk live (Berge et al., 2011; Magaisa et al., 2015).

The USA CDC (2018) has advised that people should avoid swimming or wading in freshwater in countries in which schistosomiasis occurs. Swimming in the ocean and in chlorinated swimming pools is recommended. Although schistosomiasis is not transmitted by swallowing contaminated water, if the mouth or lips come in contact with water containing the parasites, one may become infected. Water treatment is recommended before drinking. Water used for bathing should be brought to a rolling boil for 1 minute to kill any cercariae, and then cooled before bathing to avoid scalding. Vigorous towel drying after an exposure may help to prevent parasites from penetrating the skin.

In countries where schistosomiasis causes significant disease, control efforts usually focus on: reducing the number of infections in people and/or eliminating the snails that are required to maintain the parasite's life cycle (Magaisa et al., 2015). For all species that cause schistosomiasis, improved sanitation could reduce or eliminate transmission of this disease. Control measures can include mass drug treatment of entire communities and targeted treatment of schoolage children (Berge et al., 2011). Some problems exist in the control of schistosomiasis. Firstly, chemicals used to eliminate snails in freshwater sources may harm other species of animals in the water and, if treatment is not sustained, the snails may return to those sites afterwards. Secondly, for certain species of the parasite, such as $S$. japonicum, animals such as cows or water buffalo can also be infected. Runoff from pastures (if livestock are infected) can contaminate freshwater sources (Magaisa et al., 2015).

Apart from praziquantel other novel drugs and schistosomicides are still under trial (Berge et al., 2011; Ridi and Tallima, 2012; Magaisa et al., 2015) as presented in Table 3. It is highly effective in killing adult worms. Mass treatment with praziquantel in endemic areas has been shown to reduce the burden of urogenital schistosomiasis (Berge et al., 2011; Nkengazong et al., 2013). Currently, praziquantel is given as a single oral dose of $40 \mathrm{mg} / \mathrm{kg}$, with food and drink but it is expensive. Countries with successfully established schistosomiasis national control programmes using generic praziquantel supplied free of charge include Zambia, Nigeria, Mozambique and Uganda (Nkengazong et al., 2013; Magaisa et al., 2015). There has been no evidence of development of resistance to praziquantel.

WHO's work on schistosomiasis is part of an integrated approach to the control of neglected tropical diseases. Although WHO recommended large-scale distribution of praziquantel to at-risk populations living in endemic areas in the 1970s and 1980s, it was only at the 54th World Health Assembly (WHA54.19) that chemotherapy was endorsed officially as the key public-health strategy to fight schistosomiasis (Magaisa et al., 2015). Member states were advised to take effective steps to control schistosomiasis and soil transmitted helminthes with the following mandates:

- To sustain successful control activities in lowtransmission areas in order to eliminate schistosomiasis and soil-transmitted helminth infections as a public-health problem 
- To give high priority to implementing or intensifying control of schistosomiasis and soiltransmitted helminth infections in areas of high transmission while monitoring drug quality and efficacy

- To ensure access to essential drugs against schistosomiasis and soil-transmitted helminth infections in all health services in endemic areas for the treatment of clinical cases and groups at high risk of morbidity such as women and children, with the goal of attaining a minimum target of regular administration of chemotherapy to at least $75 \%$ and up to $100 \%$ of all school-age children at risk of morbidity.

- To promote access to safe water, sanitation and health education

- To ensure that any development activity likely to favour the emergence or spread of parasitic diseases is accompanied by preventive measures to limit its impact

\section{WHO strategic plan to eliminate schistosomiasis by} 2025

Over the years, several countries have implemented schistosomiasis control programmes successfully. These countries include Brazil, Burkina Faso, China, Egypt and Uganda ( ). Significant reduction in urogenital schistosomiasis infection and morbidity has been achieved by mass treatment. In countries that have not been able to successfully control schistosomiasis, the major obstacle has been limited access to praziquantel as well as unavailability of water, sanitation, environmental health infrastructure or the necessary resources to implement schistosomiasis control (Magaisa et al., 2015). The WHO came up with a strategic plan to eliminate schistosomiasis in endemic countries by 2025 . One of the goals is to successfully control schistosomiasis morbidity by 2020 . This goal has been defined as $75 \%$ national coverage for schistosomiasis control and less than $5 \%$ prevalence of heavy infections recorded in endemic countries. If this goal is achieved by 2020 , it may be possible to eliminate schistosomiasis as a public-health problem by 2025 . By increasing schistosomiasis control activities in endemic areas and ensuring an adequate supply of praziquantel and the other resources required, this goal is attainable (Magaisa et al., 2015). The monitoring and evaluation of schistosomiasis control can be undertaken by local health facilities. Primary health facilities and school health teams across the country should be supplied with praziquantel for treating infected patients. The communities should also be provided with potable water in order to avoid contact with contaminated water as well as adequate sanitation to decrease contamination of water bodies. Ridi and Tallima (2012) have proposed the use of polyunsaturated fatty acid, arachidonic acid (ARA) as a remedy for schistosomiasis. The vaccines are larval excreted-secreted products and are entirely accessible to the host immune system effector elements. These will likely lead to development and implementation of a sterilizing vaccine in a near future. Promising novel drugs and schistosomicides are presented in Table 3.

Table 3 Schistosomicides target and mechanism of action.

\begin{tabular}{ll}
\hline Drug & Mode of Action \\
\hline Antimonials & Inhibition of schistosome phosphofructokinase \\
Metrifonate & Schistosome acetylcholinesterase inhibition and paralysis \\
Oxamniquine & Mediates inhibition of parasite DNA and RNA synthesis \\
Praziquantel & Still elusive; binding to parasite calcium channels. Binding and polymerization of actin. \\
& Exposure of surface membrane antigens \\
Artemether & Inhibits hemozoin formation \\
Acyclic-nucleotide analogues & Inhibit parasite DNA polymerase \\
Oxadiazoles & Inhibit parasite thioredoxin-glutathione reductase \\
Trioxaquines & Alkylation of, and stacking with, heme \\
\hline Sourced from: Ridi and Tallima (2012)
\end{tabular}

\section{Conclusion}

Schistosomiasis, a neglected Tropical disesae caused by species of Schistosoma has remained a big public health challenge in the Sub-Saharan African countries. The level of hygiene in most African countries is still quite low while frequent contacts with freshwater bodies that are polluted with snails hosts are inevitable. This has resulted in the high prevalence levels reported in many locations across Africa. Advances in methods of diagnosis have gone a long way to monitor the infections very rapidly. However, many life threatening complications are still linked to schistosomiasis. The situation becomes aggravated by co-infection of schistosomes with other parasites. It is hoped that the renewed efforts of global health agencies such as WHO in the control of schistosomiasis would help alleviate the impacts and if possible eliminate the burden in the nearest future. African countries are strongly advised to adhere to the guidelines issued by WHO and CDC most especially on campaign/awareness, mass literacy and public health education of citizens geared towards the prevention, treatment and control of schistosomiasis. The future control measure of schistosomiasis is likely to be based on the discovery and adoption of cheap novel drugs, schistosomicides and vaccines to combat the worrisome infection in the sub Saharan Africa and other places in the Tropics. 


\section{References}

1. Abebe, N., Erko, B., Medhin, G., Berhe, N. (2014) Clinicoepidemiologicalstudy of Schistosomiasis mansoni in WajaTimuga, District of Alamata, northern Ethiopia. Parasit Vectors, 7:158

2. Adenowo, A.F., Oyinloye, B.E., Ogunyinka, B.I., Kappo, A.P. (2015). Impact of human schistosomiasis in sub-Saharan Africa. The Brazilian Journal of Infectious Diseases, 1 9(2):196-205

3. Adeyeba, O.A. and Ojeaga, S.G. (2002). Urinary Scistosomiasis and Concomitant Urinary Tract Pathogens Among School Children in Metropolitan Ibadan, Nigeria. African Journal of

Biomedical Research, 5: 103-107.

4. Anto, F., Asoala, V., Adjuik, M. (2013). Water contact activities andprevalence of schistosomiasis infection among school-agechildren in communities along an irrigation scheme in ruralNorthern Ghana. J Bacteriol Parasitol., 4:177.

5. Augusto, G., Nala, R., Casmo, V., Sabonete, A., Mapaco, L., Monteiro, J. (2009). Geographic distribution and prevalence of schistosomiasisand soil-transmitted helminths among school children inMozambique. Am J Trop Med Hyg., 5:799803

6. Berge, S., Kabatereine, N., Gundersen, S.G, Taylor, M. Kvalsvig, J.D., Mkhize-Kwitshana, Z. (2011). Generic praziquantel in South Africa: The necessity for policy change to provide cheap, safe and efficacious schistosomiasis drugs for the poor, rural population. Review. South Afr J Epidemiol Infect., 26(1):22-25.

7. Chistulo, L., Loverde, P., Engels, D. (2004). Disease Watch: Schistosomiasis. TDR Nature Reviews Microbiology, 2:12

8. Colley, D.G., Loverde, P.T., Savioli, L. (2001). Medical Helminthology in The 21st Century. Science, 293: 14371438

9. Corachan, M. (2002). Schistosomiasis and international travel. Clinical Infectious Disease, 35(4):446-50.

10. Fenwick, A., Webster, J.P., Blair, L., Fleming, F.M., Zhang, Y., Garba, A.(2002). The schistosomiasis control initiative (SCI): Rationale, development and implementation from 2002-2008. Parasitology, 136(13):1719-1730

11. Friedman, J.F., Mital, P., Kanzaria, H.K., Olds, G.R., Kurtis, J.D. (2007). Schistosomiasis and pregnancy. Trends in Parasitology, 23(4):159-64

12. Gberikon, G.M., Aguoru, C.U. And Yandev, D. (2015). Incidence of Schistosoma haematobium and Trichomonas vaginalis Among Occupational Status of Patients Attending Some Selected Hospitals in Gboko, Benue State Of Nigeria. International Journal of Sciences, 4 (6):3843

13. Gryseels, B. (1991). The epidemiology of schistosomiasis in Burundi and its consequences for control. Science Direct, 85 (5): 623-633

14. Kiran, S. amd Jitendra, S. (2016). Current status of schistosomiasis in Sokoto, Nigeria. Parasite Epidemiology and Control, 1(3): 239-244

15. Kosala,G. A. D., Weerakoon, G.N. Gobert, P.C., Donald, P. M.(2015). Advances in the Diagnosis of Human Schistosomiasis. Exp Parasitol., 139:24-32.

16. Lapa, M., Dias, B., Jardim, C., Fernandes, C.J., Dourado, P.M., Figueiredo, M. (2009). Cardiopulmonary manifestations of hepatosplenic schistosomiasis. Circulation. 119(11):1518-23

17. Leshem, E., Maor, Y., Meltzer, E., Assous, M., Schwartz, E. (2008). Acute Schistosomiasis Outbreak: Clinical Features and Economic Impact. Clinical Infectious Diseases, 47:14991506

18. Lier, T., Simonsen, G.S., Haaheim, H., Hjelmevoll, S.O., Vennervald, B.J, Johansen, M.V. (2006). Novel real-time $\mathrm{PCr}$ for detection of Schistosoma japonicum in stool. Southeast Asian Journal of Tropical Medicine and Public Health, 37(2):257-64

19. Magaisa, K., Taylor, M., Kjetland, E.F., Naidoo, P.J. (2015). A review of the control of schistosomiasis in South Africa. South African Journal of Science, 111:11-12

20. Mazigo, H.D., Waihenya, R., Mkoji, G.M. (2010). Intestinal schistosomiasis: prevalence, knowledge, attitude andpractices among school children in an endemic area of NorthWestern Tanzania. J Rural Trop Public Health, 9:53-60.

21. Mbabazi, P., Andan, O., Fitzgerald, D.W., Chitsulo, L. Engels, D., Downs, J.A.(2011). Examining the relationship between urogenital schistosomiasis and HIV infection. PLoS Negl Trop Dis., 5(12):e1396

22. Mcman, D.P. (2002): Current Concepts In Schistosomiasis, 346:1212-1220

23. Meents, E.F.and Boyles, T.H. (2010). Schistosoma haematobium prevalence inschool children in the rural Eastern Cape Province SouthAfrica. $S$ Afr J Epidemiol Infect., 25:28-9.

24. Mohammed, A,Z., Edino, S.T., Samaila, A.A. (2007) Surgical pathology of schistosomiasis. Journal of National Medical Association, 99(5):570-574.

25. Nkengazong, L., Njiokou, F., Asonganyi, T. (2013). Two years impact of single praziquantel treatment on urinary schistosomiasis inthe Barombi Kotto focus, South West Cameroon. J Parasit Vector Biol.,5:83-9.

26. Nwabueze, A.A. and Opara, K.N. (2007). Outbreak of Schistosomiasis among school children in riverine communities of Delta State, Nigeria: Impact of Road and Bridge Construction. Journal of Medical Sciences, 7: 572 578

27. Odiere, M.R., Rawago, F.O., Obok, M. (2012). High prevalence of schistosomiasis in Mbita and its adjacent islands of LakeVictoria, western Kenya. Parasit Vectors, $5: 278$

28. Otuneme, G., Akinkuade, F.O., Obebe, O.O.,Usiobuegbe, O.S., Faloye, T.G., Olasebikan, O.S., Akinleye, W.A, and Koku, O.D. (2014). A study of the prevalence of Schistosoma haematobium and Schistosoma intercalatum in a rural community in Ogun State, Nigeria. South East Asian Journal of Public Health, 4(1): 67-71

29. Ridi, A.F. and Tallima, H.A (2012). Novel Therapeutic and Prevention Approaches for Schistosomiasis: Review. Journal of Advanced Research, 4: 467-478

30. Ross. A.G.P., Bartlet, P.B., Sleigh, A.C., Adrian, C., Olds, G.R., Li, Y., Williams, G.M And

Ruberanziza, E., Mupfasoni, D., Karibushi, B. (2010). A recentupdate of Schistomiasis mansoni endemicity around LakeRweru. Rwanda Med J., 68:5-9

31. Salawu, O.T. and Odaibo, A.B. (2013). Schistosomiasis among pregnantwomen in rural communities in Nigeria. Int $J$ Gynaecol Obstet.,122:1-4.

32. Seck, S.M., Sarr, M.L., Dial, M.C., Ka, E.F. (2011) Schistosoma hematobium -associated glomerulopathy. Case Report, 21(3):201-203.

33. Senghor, B., Diallo, A., Sylla, S.N. (2014). Prevalence and intensity of urinary schistosomiasis among school children in the district of Niakhar, region of Fatick, Senegal. Parasit Vectors, 7:5.

34. Tetteh-Quarcoo, P.B., Attah, S.K., Donkor, E.S. (2013). Urinary schistosomiasis in children - still a concern in part of the Ghanaian capital city. Open J Med Microbiol., 3:151-8.

35. van Lieshout, L., Polderman, A.M,, Deelder, A.M, (2000). Immunodiagnosis of schistosomiasis by determination of the circulating antigens $\mathrm{CAA}$ and $\mathrm{CCA}$, in particular in individuals with recent or light infections. Acta Trop, 77(1):69-80

36. Walker, M., Zunt, J.R.(2005). Parasitic central nervous system infections in immunocompromised hosts. Clinical Infectious Diseases, 40(7):1005-15.

37. Yirenya-Tawiah, D.R., Annang, T., Otchere, J. (2013). Urinarys chistosomiasis among adults in the Volta Basin of Ghana:prevalence, knowledge and practices. J Trop Med Parasitol. 34:1-16.

\section{Websites}

1. http//:www.uti.standford.edu/research

2. Centre for Disease Control (2008). U.S. Department of Health \& Human Services. Accessed at: www.hhs.gov

3. World Health Organization http://www.who.int/healthinfo/globalburden disease/estimates/en/index1.html 